Research Article

\title{
Knowledge and Practices on Menstrual Hygiene Management Among Adolescent Girls of Kaski District, Nepal
}

\author{
Sasmita Poudel ${ }^{12^{*}}$, Dipesh Gautam ${ }^{3}$ \\ ${ }^{1}$ National Institute of Health and Environment, Kathmandu, Nepal, \\ ${ }^{2}$ Institute of Himalayan Risk Reduction, Lalitpur, Nepal \\ ${ }^{3}$ Tri-chandra Multiple Campus, Tribhuvan University, Nepal
}

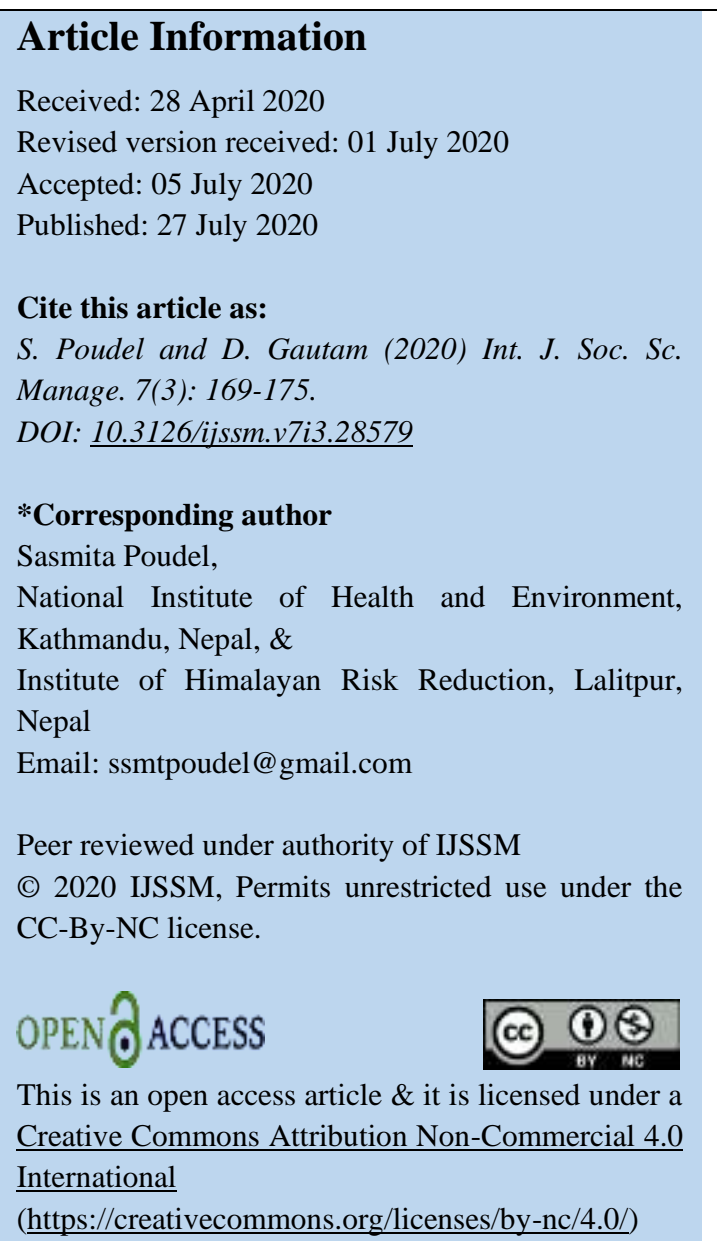

\begin{abstract}
The study was conducted to understand the cultural and social practices and knowledge prevailing on menstrual hygiene management among adolescent girls in Nepal. A school-based cross-sectional study was conducted among 122 adolescent girls of class VII to X at three schools of Kaski district, Nepal. A pretested structured questionnaire was used for assessing socio-demographic profiles, knowledge, and experiences on menstruation, practices (social and cultural) regarding menstrual hygiene management. The data collected were analysed using SPSS version 23 for windows. The mean age at menarche was found to be $12.5 \pm 0.9$. The majority $(73 \%)$ girls were aware of menstruation prior to the attainment of it. Most of them got the information from mother (45.9\%), the majority $(69.7 \%)$ used sanitary pad as the absorbents, however, most of them (78.4\%) throw the sanitary pad in the garbage. Many cultural and social taboos and restrictions were found associated with menstruation. The majority $(91.8 \%)$ were not allowed to participate in religious activities, $45.1 \%$ were not allowed to touch things in the house, twothirds $(67.2 \%)$ were not allowed to cook, and $60.7 \%$ were not allowed to enter the kitchen. Most of the adolescent girls were isolated even from normal daily activities and they were not happy with these restrictions during the menstruation. Instead, they urged the need for more support, care, and hygienic practices for proper hygiene management to lead a healthy life. This paper reflects the actual knowledge and practices prevailed in the society during menstruation and emphasizes on providing the correct knowledge on health and helping to correctly practice hygiene during menstruation.
\end{abstract}

Keywords: Menstruation; Menarche; Menstrual Hygiene; Adolescent girls; Knowledge; Cultural and social practices

\section{Introduction}

Adolescence stage is the special period of transition from childhood to adulthood which involves dramatic physical, sexual, psychological, and social developmental changes (WHO 2020). Adolescence in girls has been considered as a transition phase from girlhood to womanhood with rapid physical, biological, and behavioural changes (UNFPA 2015, WHO 2020). This transitional period is marked with the onset of menarche which is one of the important 
physiological changes that occurs in adolescent girls (UNFPA 2015). The age of menarche varies with geographical conditions, racial factors, nutritional diets, environmental factors, and involvement in physical activity (Adhikari et al., 2006). Menstrual hygiene management is the prime requirement for adolescents for a healthy life (Paul et al., 2014). Menstrual hygiene management starts with delivering awareness and information about menstruation and menstrual hygiene practices. Menstruation is a natural process; however, it has been associated with different taboos and practices around the globe (Poureslami and Osati-Ashtiani, 2002; Dasgupta and Sarkar, 2008; Thakre et al., 2011; Patle and Kubde, 2014; Udayar et al., 2016).

Menstruation is considered as unclean, a matter of shame, and bound to social taboos in the context of Nepal, and therefore practices and taboos vary between communities in Nepal (Adhikari et al., 2006; Sapkota et al., 2013). Some common practices during menstruation are excluding girls and women from regular social and cultural life such as restrictions on free mobility around houses, not being able to touch family members (especially male) and water points, exclusion from religious activities, a compulsion to sleep in the floor, etc. (Adhikari et al., 2006; Sapkota et al., 2013; Paul et al., 2014; Parajuli et al., 2016).

Adolescent girls who are transitioning from childhood to womanhood might find difficulty in coping with the practices that are prevalent in the community. Cultural and social restrictions derive girls to follow the wrong practices of hygiene management during menstruation. Also, in our society, most of the adolescent girls do not get enough information on menstruation and they are not aware of menstrual hygiene management (Sooki et al., 2016). This, directly and indirectly, contributes to infections \& problems related to sexual and reproductive health, school absenteeism, and emotional imbalance (Burbank, 2002; UNFPA, 2015). Access to enough water and soap, sanitation facilities, proper sanitary absorbents together with clear information on menstrual hygiene management, and social inclusion during menstruation will help adolescents and women for good physical health as well as psychosocial well-being (Mahon and Fernandes, 2010; Sida 2016).

The objectives of the study are to understand the cultural and social practices associated with menstruation, and knowledge prevailing on menstrual hygiene management among adolescent girls in Nepal. Hence, this study will contribute to better understand the real scenario of the society which will help to raise awareness, designs the programs, and advocate for the correct hygiene practice during menstruation.

\section{Methods}

The school-based cross-sectional study was conducted on adolescent girl students of grade VII to X at three schools of Pokhara metropolitan city, Kaski district, Nepal. Out of three schools, one was a public school and two were private schools. Schools were chosen purposively and a universal sampling technique was used to include all the adolescent girl students studying in standard VII-X of selected schools which resulted in a total of 122 samples for the study. A pilot study was conducted among $10 \%$ of the total sample and their findings were not included for the analysis of this study. A Pre-tested structured questionnaire was used for assessing socio-demographic profile, knowledge, and experiences on menstruation, social and cultural practices regarding menstruation and practices on hygienic practices for menstrual hygiene management. Written informed consent from the principle of the school and assent from the students who were willing to participate were taken before the study was initiated. The quantitative data collected were processed and analysed using proportions with Statistical Package for Social Sciences (SPSS) version 23 for windows.

\section{Results}

\section{Socio-Demographic Findings}

The findings show that the age of the adolescent girls in the study ranges from 12 years to 18 years, maximum respondents $(46.7 \%)$ belong to the age of $14-15$ years. The mean age of the students was nearly 14.35 years. The majority of respondents $(86.9 \%)$ belonged to the Hindu religion, less than half $(45.1 \%)$ belonged to Brahmin/ Chettri ethnicity, and $77 \%$ belonged to the nuclear family. The respondents' fathers were found to be more educated than their mothers. Out of the total, $47.5 \%$ of the respondents' fathers had an education of secondary level whereas $38.5 \%$ of the mothers' education level was up to the primary level, and $10.7 \%$ were illiterate.

\section{Knowledge and Experiences on Menstruation}

The mean age at menarche was found to be $12.5 \pm 0.9$ whereas the perceived normal age of menarche by adolescent girls was $14.38 \pm 1.815$. Among the respondents, a majority $(83.7 \%)$ of adolescent girls had correct knowledge about menstruation, however only $73 \%$ of girls were aware of menstruation prior to attainment of it. Most of the respondents $(45.9 \%)$ who were aware of menstruation prior to attainment of it received the information from mothers. Similarly, maximum respondents $(81.1 \%)$ shared first with their mothers about menarche, over one-thirds were confused $(37.7 \%)$ and frightened $(38.5 \%)$ at their menarche (Table 1).

Tiredness and back pain were found to be the most common problems followed by $34.4 \%$ dysmenorrhoea. For the remedial measures for problems during menstruation, most 
of them $(75.4 \%)$ maintained personal hygiene (Table 1). Among the total respondents on knowledge of menstruation, $50.8 \%$ defined it as a monthly cycle where blood flows from the uterus for 4-5 days in every adolescent female (Table 2).

Table 1 Knowledge and experiences on different aspects of menstruation

\begin{tabular}{|c|c|c|c|}
\hline Characteristics & Categories & Number & Percent \\
\hline Definition of menstruation & Correct answer & 122 & 83.7 \\
\hline $\begin{array}{l}\text { Aware about menstruation prior to } \\
\text { attainment of menarche }\end{array}$ & Yes & 89 & 73 \\
\hline \multirow{4}{*}{$\begin{array}{l}\text { First person with whom respondent share } \\
\text { about their menarche }\end{array}$} & Mother & 99 & 81.1 \\
\hline & Sisters & 15 & 12.3 \\
\hline & Friends & 6 & 4.9 \\
\hline & Other relatives & 2 & 1.6 \\
\hline \multirow[t]{4}{*}{ Experience at Menarche } & Confusing & 46 & 37.7 \\
\hline & Expectant & 27 & 22.1 \\
\hline & Frightened & 47 & 38.5 \\
\hline & Others(specify) & 2 & 1.6 \\
\hline \multirow[t]{3}{*}{ Attitude toward Menarche } & Undesirable & 27 & 22.1 \\
\hline & Unprepared & 45 & 36.9 \\
\hline & Satisfactory & 50 & 41 \\
\hline \multirow[t]{3}{*}{ Days of usual flow of menstruation } & 2-3 days & 20 & 16.4 \\
\hline & 4-5 days & 70 & 57.4 \\
\hline & More than 5 days & 32 & 26.2 \\
\hline \multirow[t]{6}{*}{ Source of information* } & Mother & 56 & 45.9 \\
\hline & Teachers/books & 41 & 33.6 \\
\hline & Sisters & 10 & 8.2 \\
\hline & Friends & 9 & 7.4 \\
\hline & Radio/F.M/television & 3 & 2.5 \\
\hline & Health workers & 4 & 3.3 \\
\hline \multirow[t]{4}{*}{ Problems faced during menstruation* } & Dysmenorrhoea & 42 & 34.4 \\
\hline & Loss of appetite & 23 & 18.8 \\
\hline & Tired and Back pain & 91 & 74.5 \\
\hline & Excessive blood loss & 23 & 18.8 \\
\hline \multirow[t]{5}{*}{$\begin{array}{l}\text { Remedial measures for problems } \\
\text { during menstruation* }\end{array}$} & $\begin{array}{l}\text { Maintain } \\
\text { hygiene }\end{array}$ & 92 & 75.4 \\
\hline & Take rest & 43 & 35.2 \\
\hline & $\begin{array}{l}\text { Drink lots of water / eat } \\
\text { fruits }\end{array}$ & 30 & 24.6 \\
\hline & Exercise & 9 & 7.4 \\
\hline & Take medicines & 8 & 6.6 \\
\hline
\end{tabular}

* Overall percentage exceeds as it was multiple choice question hence analysis is done taking each source, symptoms and problems to be $100 \%$ 
Table 2: Knowledge about menstruation

\begin{tabular}{llc}
\hline Description & Number & Percent \\
\hline $\begin{array}{l}\text { Monthly cycle where blood flows from the uterus for 4-5 days } \\
\text { in every adolescent female }\end{array}$ & 52 & 50.8 \\
Blood coming from vagina & 4 & 3.3 \\
Monthly flow of dirty blood from uterus or vagina & 20 & 16.4 \\
Natural process occurring in every adolescent female & 34 & 27.9 \\
A sign of maturity, flow of blood from urethra & 2 & 1.6 \\
\hline Total & $\mathbf{1 2 2}$ & $\mathbf{1 0 0}$ \\
\hline
\end{tabular}

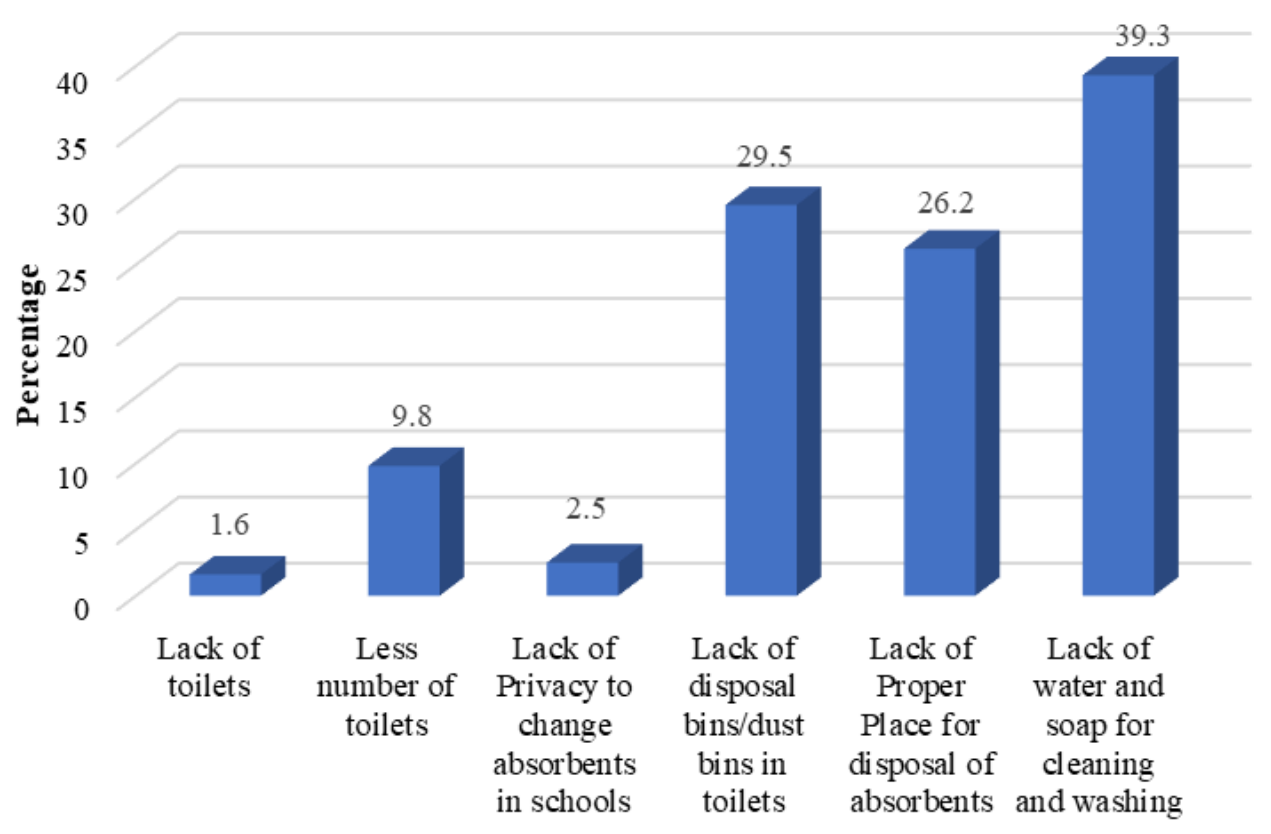

Fig. 1: Problem faced in school during menstruation

\section{Practices Regarding Menstrual Hygiene}

The findings on practice of menstrual hygiene among adolescent girls showed that $69.7 \%$ used sanitary pad, $4.9 \%$ used cloth, and $25.4 \%$ used both sanitary pad and cloth as the absorbents during menstruation. Among the total respondents using the cloth absorbents, more than a half $(56.76 \%)$ used to wash cloth with soap and water and dry it in the sun while one-fifth $(21.62 \%)$ used to wash cloths and dry where other people can't see. Most of the adolescent girls $(59.8 \%)$ changed absorbents twice a day. On the practice related to the frequency of bathing during menstruation, it was found that a majority $(68 \%)$ used to bath directly on the third day and only $23 \%$ bathed daily.
Moreover, it was found that most of the respondents $(72.2 \%)$ cleaned their external genitals frequently (2-3 times a day) and some of the respondents (9.8\%) cleaned their external genitals rarely (once in 2-3 days/while bathing) during their menstruation (Table 3). Almost all $(98.4 \%)$ of adolescent girls in this study do not miss their schools during menstruation. It was reported that $1.6 \%$ of adolescent girls who missed their schools during menstruation were due to dysmenorrhoea. Adolescent girls mentioned some problems faced in school during menstruation (Fig. 1). 
Table 3 Hygiene practices during menstruation

\begin{tabular}{|c|c|c|c|}
\hline Characteristics & Categories & Number & Percent \\
\hline \multirow{3}{*}{$\begin{array}{l}\text { Type of absorbents used during } \\
\text { menstruation }(n=122)\end{array}$} & Sanitary pad & 85 & 69.7 \\
\hline & Cloth & 6 & 4.9 \\
\hline & Both sanitary pad and cloth & 31 & 25.4 \\
\hline \multirow[t]{5}{*}{$\begin{array}{l}\text { Method of disposal of cloth absorbents } \\
(n=37)\end{array}$} & $\begin{array}{l}\text { Wash cloth with soap and water } \\
\text { and dry it in sun }\end{array}$ & 21 & 56.6 \\
\hline & $\begin{array}{l}\text { Wash cloths and dry where } \\
\text { other people can't see }\end{array}$ & 8 & 21.62 \\
\hline & $\begin{array}{l}\text { Throw the used cloth } \\
\text { absorbents to garbage }\end{array}$ & 5 & 13.51 \\
\hline & Burn the cloth & 2 & 5.41 \\
\hline & Wash and dry in dark rooms & 1 & 2.7 \\
\hline \multirow{3}{*}{$\begin{array}{l}\text { Method of disposal of sanitary pad } \\
\text { absorbents }(n=116)\end{array}$} & Throw in garbage & 91 & 78.40 \\
\hline & Burn pad & 14 & 12.1 \\
\hline & Dispose pad in pit & 11 & 9.5 \\
\hline \multirow{3}{*}{$\begin{array}{l}\text { Frequency of changing absorbents per } \\
\text { day }(n=122)\end{array}$} & once a day & 11 & 9.1 \\
\hline & twice a day & 73 & 59.8 \\
\hline & $\geq 3$ times a day & 38 & 32.1 \\
\hline \multirow{3}{*}{$\begin{array}{l}\text { Practice of bathing during menstruation } \\
(\mathrm{n}=122)\end{array}$} & Daily & 28 & 23 \\
\hline & Once in third day & 83 & 68 \\
\hline & Once directly on fourth day & 11 & 9 \\
\hline \multirow{3}{*}{$\begin{array}{l}\text { Practice on cleaning external genital } \\
\text { during menstruation }(\mathrm{n}=122)\end{array}$} & Frequently (2-3 times a day) & 88 & 72.2 \\
\hline & Occasionally (once a day) & 22 & 18 \\
\hline & $\begin{array}{l}\text { Rarely (once in 2-3 days/while } \\
\text { bathing) }\end{array}$ & 12 & 9.8 \\
\hline
\end{tabular}

\section{Social and Cultural Practices During Menstruation}

Many cultural and social restriction prevailing during menstruation was found. A majority (91.8\%) were not allowed to go to a temple/ participate in religious activities, nearly half $(45.1 \%)$ were not allowed to touch things in the house, two-thirds $(67.2 \%)$ were not allowed to cook and $60.7 \%$ were not allowed to enter the kitchen. Similarly, $38.5 \%$ were not allowed to touch/sit/talk with a male member of the family, $34.4 \%$ were not allowed to stay/ go in other's house, $24.6 \%$ were using/wearing older clothes, $22.1 \%$ were using older cuisines/mattress/blankets to sit and sleep during menstruation. Also, it was found that nearly half $(45.9 \%)$ were allowed to enter the kitchen after taking bath on $4^{\text {th }}$ day during menstruation. About, $17.2 \%$ were practicing staying away in a separate place away from home or in corner of the house, $14.8 \%$ were restricted to go to field or play, and $24.6 \%$ were not allowed to sleep on their own bed. Those who were not allowed to sleep on their own bed were sleeping either on the floor or in a separate bed. A few $(7.4 \%)$ faced different restrictions on diet during menstruation. Different diet restrictions during menstruation such as not allowed to eat meat (4.1\%), not allowed to drink enough water $(0.8 \%)$, and not allowed to eat spicy and sour food (2.4\%) were reported. Besides these, other restrictions mentioned by respondents were "not allowed to see the sun during first menstruation", "hide during first menstruation", and "not allowed to touch water" during menstruation.

\section{Discussion}

In this study, the mean age at menarche was $12.5 \pm 0.9$ and perceived age of menarche was $14.38 \pm 1.815$ which was similar to the findings from other studies which had reported the mean age at menarche to be $12.69 \pm 0.95$ (Sunuwar et al., 2010) and 13.1 \pm 0.9 (Sapkota et al., 2013). Likewise, the perceived normal age of menarche was 12.5 \pm 2.5 (Sapkota et al., 2013) and 12 years (Parajuli et al., 2016). Regarding knowledge and experiences related to menstruation, the finding of the present study showed that 
majority $(50.8 \%)$ of the respondents considered menstruation as a monthly cycle where blood flows from the uterus for 4-5 days in every adolescent female which is slightly different from the findings of the study $(36 \%)$ (Sapkota et al., 2013). The finding contrasts with a previous study (Adhikari et al. 2006) where only 6\% of girls reported that menstruation is a normal physiological process. The findings of this study that $73 \%$ girls were aware about menstruation prior to menarche, mother as the main source of information (45.9\%), and the majority shared their first menarche experience with their mothers are concurrent with the findings from similar studies (Sapkota et al., 2013; Parajuli et al., 2016). All other findings of this study regarding problems faced during menstruation and remedial measures applied were similar except the finding that dysmenorrhea was the most common problem among school-going adolescents of rural Nepal (Sapkota et al., 2013).

This study showed that the majority $(69.7 \%)$ of the girls used sanitary pads as absorbent during menstruation. Only $4.9 \%$ of girls used cloth absorbents during menstruation while $25.4 \%$ used both sanitary pad and cloth as absorbents. The study conducted in Gujarat reported $60 \%$ of girls used sanitary pads (Ninama and Dund, 2015). Findings of other studies (Sapkota et al., 2013; Parajuli et al., 2016) conducted in rural Nepal showed less percentage $(33.3 \%$ and $54.1 \%$ of girls using the sanitary pad as absorbents) which is different from the findings of this study. The reason is due to the urban and rural context of the study, the present study was conducted in the urban areas. In addition to the above hygiene practices, most of the girls (59.8\%) in this study changed their absorbents twice a day which was slightly higher than the findings from a similar study (Sapkota et al., 2013). The practice in terms of cleaning the external genital daily seems good in comparison to the frequency of changing absorbents and the practice of bathing.

In this study, a majority of the respondents (91.8\%) were not allowed to enter the temple or participate in religious activities. This finding is similar with the previous study conducted at Morang, Nepal where $94.1 \%$ girls were not allowed to perform religious activities (Parajuli et al., 2016), however, another study conducted at Sunsari, Nepal showed much less (41\%) (Sapkota et al., 2013). Other findings and restrictions on the social and cultural practices in the present study were similar to different studies (Parajuli et al., 2016; Udayar et al., 2016) while it is slightly higher than the study conducted in Sunsari, Nepal (Sapkota et al., 2013). In the present study, almost all (98.4\%) adolescent girls do not miss their schools during menstruation which is slightly higher than the finding (91.2\%) of the other study (Parajuli et al., 2016).
Various interesting findings such as only $73 \%$ of adolescent girls knowing about menarche, only $41 \%$ girls prepared for it while most of them were frightened during menarche indicated that there is lack of proper information to girls before menarche. Unsafe practices and many restrictions regarding menstruation was found to be common problems. Most of the adolescent girls were not happy with the social and cultural restrictions such as entering the kitchen, performing religious activities, touching a male family member, etc. during the menstruation. They mentioned that these practices on the ground of social and cultural practices should be changed and our culture should accept menstruation as a natural physiological process. Furthermore, they added that women and girls should be provided facilities and opportunities for a clean and hygienic environment, access to normal activities with proper care rather than abstaining during menstruation.

\section{Conclusion}

Menstruation has been dealt with secrecy and negative responses such as shame, fear, anxiety, and depression. The present study concludes that there is a huge gap in the knowledge to prepare adolescent girls for menarche. The clear information on menstruation and the correct hygienic practices are found to be lacking which is a great risk towards the reproductive health of adolescent girls. Adolescent girls, their mothers, and other family members can play an important role in improving menstrual hygiene management in the community. Hence, they need to be given awareness with correct and proper information on menstruation, its occurrence, and hygienic practices during menstruation. The cumulative efforts on breaking the silence and taboos associated with menstruation from all sectors are of utmost importance for improving the health conditions and hygienic practices during menstruation in Nepal.

\section{References}

Adhikari P, Kadel B, Dhungel SI and Mandal A (2006) Knowledge and practice regarding menstrual hygiene in rural adolescent girls of Nepal. Kath. Uni. Med. J. 5: 382386.

Burbank J (2002) Puberty in Cultures of the World Nepal. Marshall Cavendish Children's Books.

Dasgupta A and Sarkar M (2008) Menstrual hygiene: how hygienic is the adolescent girl?. Indian J. Community Med. 33: 77.

Mahon T and Fernandes M (2010) Menstrual hygiene in South Asia: a neglected issue for WASH (water, sanitation and hygiene) programmes. Gender \& Development 18: 99113.

Ninama R and Dund JV (2015) Knowledge and Practice Regarding Menstrual Hygiene among Adolescent Girls in Schools of Patan, Gujarat. Sch. J. App. Med. Sci. 3:27049. 
Parajuli P, Paudel N and Shrestha S (2016) Knowledge and practices regarding menstrual hygiene among adolescent girls of rural Nepal. J. Kath. Med. College 5: 23-27.

Patle R and Kubde S (2014) Comparative study on menstrual hygiene in rural and urban adolescent. Int. J of Med. Sci. Public Health 3: 129-133.

Poureslami M and Osati-Ashtiani F (2002) Assessing knowledge, attitudes, and behavior of adolescent girls in suburban districts of Tehran about dysmenorrhea and menstrual hygiene. J. Intl. Women's Studies 3: 51-61.

Paul D, Patnaik R, Gopalakrishan S (2014 ) Improvement in Knowledge and Practices of Adolescent Girls Regarding Reproductive Health with Special Emphasis on Hygiene during Menstruation in Five Years. Health and Population-Perspectives and Issues 37: 1-15

Sapkota D, Sharma D, Pokharel H, Budhathoki SS and Khanal VK (2013) Knowledge and practices regarding menstruation among school going adolescents of rural Nepal. J. Kath Med. College 2:122-128.

Sida (2016) Menstrual Hygiene Management. [Available from: https://www.sida.se/contentassets/2d05faf3aebc4092a0ef 96439c026262/18565.pdf]
Sooki Z, Shariati M, Chaman R, Khosravi A, Effatpanah M and Keramat A (2016) The role of mother in informing girls about puberty: a meta-analysis study. Nurs. Midwifery Stud. 5:e30360

Sunuwar L, Saha CG, KC A and Upadhyay DK (2010) Age at menarche of subpopulation of Nepalese girls. Nep. Med. Coll. J. 12: 183-186.

Thakre SB, Thakre SS, Reddy M, Rathi N, Pathak K and Ughade $S$ (2011) Menstrual hygiene: knowledge and practice among adolescent school girls of Saoner, Nagpur district. J Clin Diagn Res 5: 1027-1033.

Udayar SE, Kruthika K and Devi PV (2016) Menstrual hygiene practices among adolescent girls residing in tribal and social welfare hostel in Andhra Pradesh: A community based study. Natl. J. of Community Med 7: 681-685.

UNFPA (2015) Meeting the sexual and reproductive health needs of adolescent girls." [Available from https://www.unfpa.org/sites/default/files/resourcepdf/EN-SRH\%20fact\%20sheet-Adolescent.pdf.]

World Health Organization (2020) Adolescent health. [Available from http://www.searo.who.int/entity/child_adolescent/topics/a dolescent_health/en/.] 